\title{
Multiple Toll-Spätzle Pathways in Drosophila melanogaster Immunity
}

2

$5{ }^{1}$ Division of Cell Biology and Biophysics, School of Biological Sciences, University of

$7 \quad{ }^{2}$ School of Life Sciences, Central China Normal University, Wuhan 430079, China

$8{ }^{3}$ Guangzhou Key Laboratory of Insect Development Regulation and Application Research,

9 Institute of Insect Science and Technology \& School of Life Sciences, South China

10 Normal University, Guangzhou 510631, China

$1{ }^{4}$ State Key Laboratory of Silkworm Genome Biology, Southwest University, Chongqing 400716, China

$13{ }^{5}$ Department of Entomology, University of Georgia, Athens, GA 30602, USA

$14{ }^{6}$ Program in Molecular Medicine, University of Massachusetts Medical School, Worcester, MA 01605, USA

17 * Correspondence should be addressed to: M.R. Strand (email: mrstrand@uga.edu) or X.Q.

$18 \quad$ Yu (email: $\underline{\text { Yux@umkc.edu }})$

19 Running title: Multiple Toll-Spätzle pathways 


\section{Abstract}

The Drosophila melanogaster Toll-Spätzle pathway plays an important role in development and immunity. Drosophila genome encodes nine Toll receptors and six Spätzle (Spz) proteins, and only the canonical Toll-Spz (Toll-1-Spz-1) pathway has been well investigated. In this study, we compared the nine Drosophila Tolls and showed that similarly to Toll, Toll-7 also strongly activated drosomycin promoter. Importantly, we showed that both Toll and Toll-7 interacted with Spz, Spz-2 and Spz-5, and co-expression of Toll or Toll-7 with Spz, Spz-2 and Spz-5 activated the drosomycin promoter. Furthermore, Toll and Toll-7 both recognized vesicular stomatitis virus (VSV) by binding to the VSV glycoprotein. Septic infection in Toll and Toll-7 mutant flies suggested that Toll and Toll-7 differentially affected defense responses in adult males and females after systemic infection by Enterococcus faecalis, Pseudomonas aeruginosa, Candida albicans or VSV. Our results suggest multiple Toll family members activate the expression of antimicrobial peptides. Our results also provide evidence that Toll and Toll-7 bind multiple Spätzle proteins and differentially affect immune defense against different pathogens in adult male and female flies.

Keywords: Antimicrobial peptide/Innate immunity/Spätzle/Toll/Vesicular stomatitis virus 


\section{Introduction}

The defense system in Drosophila melanogaster can discriminate among various microorganisms and express antimicrobial peptides (AMPs) in response to microbial infection [1,2]. A genetic analysis has revealed that the expression of AMPs is controlled by signaling pathways, such as the spätzle/toll/tube/pelle/cactus gene cassette, which controls for example drosomycin expression [3]. Toll (also called Toll-1) was first identified in Drosophila as the receptor that regulates the dorsal-ventral patterning in embryonic development [4] and was later found to be involved in the regulation of AMP genes in larvae and adult flies [3].

Since the discovery of Drosophila Toll, more than nine Toll-like receptors (TLRs) have been identified in humans and other vertebrate species. Tolls/TLRs are present in all metazoans [5] and mediate important physiological processes, such as inflammation, immune cell regulation, cell survival, and cell proliferation [6-8]. Drosophila Toll and mammalian TLRs share a common structural architecture with a conserved ectodomain composed of leucine-rich repeats (LRRs), a single-pass transmembrane domain, and a cytosolic Toll-interlukin-1 receptor homology (TIR) domain, which is also shared by members of the interleukin-1 receptor (IL-1R) family and the intracellular adaptor protein MyD88 $[9,10]$. However, Drosophila Toll and mammalian TLRs show differences in their binding to ligands. Drosophila Toll binds to an endogenous protein ligand called Spätzle (Spz, also called Spz-1) [11,12], whereas mammalian TLRs directly recognize various pathogen-associated molecular patterns (PAMPs), such as bacterial lipopolysaccharide (LPS), 
60

61

62

63

64

65

66

67

68

69

70

71

72

73

74

peptidoglycan (PGN), teichoic acid, flagella and CpG DNA, and viral single-stranded and double-stranded RNAs [13-15].

The Drosophila genome encodes nine Tolls [16,17] and six Spätzles [18], and only the functions of the canonical Toll-Spz (also called Toll-1-Spz-1) pathway in development and innate immunity have been well studied. Drosophila Toll-2 (18 wheeler, 18W), Toll-5 (Tehao), Toll-8 (Tollo) and Toll-9 may play a role in immunity [16,19-23], Toll-6 and Toll-7 function as neurotrophin receptors and interact genetically with the Drosophila neurotrophins DNT1 (Spz-2) and DNT2 (Spz-5) [24]. Toll-7 can recognize vesicular stomatitis virus (VSV) and induce antiviral autophagy independently of the canonical Toll pathway [25], but it is not required in the response to anti-VSV infection [26].

In Drosophila, Toll activation by Spz is transduced by the adaptor protein MyD88 (dMyD88) via Tube and Pelle kinases to induce the phosphorylation and subsequent degradation of the I $\kappa$ B inhibitor Cactus [27]. Cactus degradation frees the NF- $\kappa \mathrm{B}$ factors Dif and/or Dorsal, which translocate(s) to the nucleus to activate the expression of AMP genes [28,29]. Spätzle is synthesized as a pro-protein with an $\mathrm{N}$-terminal prodomain and a C-terminal active cystine knot domain (a.k.a. the cystine-knot family of growth factors), and the activation of pro-Spz requires proteolytic cleavage [30,31]. Drosophila pro-Spz (also called pro-Spz-1) is activated by a Spätzle-processing enzyme (SPE) to generate the cystine knot active Spz [32]. Active Spz dimers bind to two Toll receptors to trigger the downstream signaling pathway $[12,33,34]$, but a direct interaction between different Toll and other Spz proteins has not yet been reported. 
Spz-6 as ligands for the activation of the Toll pathway in Drosophila innate immunity have not yet been reported. interacted with Spz, Spz-2 and Spz-5, and multiple pairs of Spz proteins with Toll or Toll-7 binding to the VSV glycoprotein; Toll and Toll-7 differentially affected defense responses in adult male and female flies after systemic infection by Enterococcus faecalis, Pseudomonas aeruginosa, Candida albicans or VSV. Our results suggest multiple Toll family members activate the expression of antimicrobial peptides. Our results also provide evidence that Toll and Toll-7 bind multiple Spz proteins and differentially affect immune defense against different pathogens in adult male and female flies.

Results

TIR domains of Drosophila Tolls activate the drosomycin but not the diptericin promoter in $\mathbf{S} 2$ cells 
Dorsal/Dif into the nucleus to activate AMP genes, such as drosomycin [28,29].

(Fig 1C). These results suggested that all nine Drosophila Tolls play a role in immune drosomycin promoter. 
previously showed that Toll receptors interact with the active cystine knot domains of Spätzles in the cell lysates and not in the cell culture media (Fig EV2). Co-IP assays showed that Toll ${ }^{\text {ecto }}$ interacted with Spz, Spz-2 and Spz-5 but not with Spz-3, Spz-4 or Spz-6 (Fig 2A-D), whereas

These findings suggested that Toll and Toll-7 can bind to multiple Spz ligands.

\section{Multiple Toll-Spz and Toll-7-Spz pairs activate the drosomycin promoter in S2 cells}

Spz, Spz-2 and Spz-5 activated the drosomycin promoter, and the highest activity was obtained 
143 These results are consistent with those obtained with the interaction of Toll and Toll-7 with

144 Spz, Spz-2 and Spz-5 (Fig 2). We also confirmed that the overexpression of Tolls (Toll, Toll-2 and Toll-7) or Spz proteins (Spz, Spz-2 and Spz-5) alone, and the co-expression of Toll-2 and Spz (non-functional pair) did not activate the drosomycin promoter, and that only the co-expression of the correct pairs of Toll and Spz proteins (Toll-Spz, Toll-7-Spz and Toll-7-Spz-5) activated the drosomycin promoter (Fig 3C). The expression or co-expression of all these proteins did not activate the diptericin promoter (Fig 3).

Ectodomains of Toll and Toll-7 recognize VSV, and VSV infection activates AMP gene

promoters

Toll-7 can recognize VSV but is not involved in the anti-VSV response [25,26]. We first determined whether Toll can also recognize VSV. Toll ${ }^{\text {ecto }}$ and Toll- $7^{\text {ecto }}$ were overexpressed in S2 cells and secreted into the cell culture media, and the VSV glycoprotein (VSV-G) was detected in the virus-infected DMEM cell culture media (Fig 4A). When the cell culture media containing Toll ${ }^{\text {ecto }}$ and Toll- $7^{\text {ecto }}$ were mixed with VSV virions and the V5-tagged ectodomains were pulled down by anti-V5 antibody, Toll ${ }^{\text {ecto }}$ and Toll- $7^{\text {ecto }}$ were detected in the immunoprecipitated proteins (Fig 4B), and VSV-G was also detected in the interaction with VSV-G. When stable S2 cell lines expressing full-length Toll and Toll-7 were transfected with AMP gene promoter reporters, the activity of the AMP gene promoters, including drosomycin and attacin promoters, were significantly activated by VSV infection 
163

164

165

166

167

168

169

170

171

172

173

(Fig 4D and E), suggesting that the recognition of VSV by Toll and Toll-7 can activate AMP genes.

\section{Toll and Toll-7 play differential roles in male and female flies to defend against bacterial,}

\section{fungal and VSV infection}

To verify the functions of Toll and Toll-7 in Drosophila immunity, wild-type $\left(w^{1118}\right)$ flies, various Toll mutants $\left(\mathrm{Tlr}^{632} / \mathrm{Tl}^{I-R X A}\right.$ and $\left.T l^{I-R X A} / T M 6 B\right)$ and Toll-7 mutants $\left(\right.$ Toll- $7^{\text {gl-5 }} / C y O$ and $D f(2 R) B S C 22 /$ Toll $\left.7^{g 1-5}\right)$ were infected with the pathogenic bacteria $E$. faecalis and $P$. aeruginosa, C. albicans, or VSV-GFP, and the cumulative survival of the flies was recorded. In $w^{1118}$ flies, Toll was expressed at a slightly lower level than Toll-7 in males but at a significantly higher level than Toll-7 in females (Fig EV4A). Therefore, septic infection assays were separately performed in male and female flies. Compared with $w^{1118}$ flies, all four mutant males and the two Toll mutant females were significantly more susceptible to E. faecalis infection (Fig 5A and E). In addition, the two Toll mutant males were significantly more susceptible to E. faecalis infection than the two Toll-7 mutant males (Fig 5A), and the two Toll-7 mutant males were significantly more susceptible to $P$. aeruginosa infection than the two Toll mutant males (Fig 5B). Moreover, all four mutant males and the two Toll mutant females were significantly more susceptible to C. albicans infection (Fig 5C and G), and the Df/Toll- $7^{g 1-5}$ and $T l r^{632} / T l^{I-R X A}$ males and all four mutant females were significantly more susceptible to VSV-GFP infection (Fig 5D and H). Additionally, the two Toll mutant females were significantly more susceptible to VSV-GFP infection than the two Toll-7 mutant females (Fig $5 \mathrm{H})$. The detection of $g f p$ transcript expression in the VSV-GFP infected flies revealed no 

post-infection (Fig EV3), indicating that the VSV-GFP titer remains at a similar level in these required for both Drosophila males and females in defense against microbial infections. Toll and Toll-7 transcripts in $w^{1118}$ males and females (Fig EV4A) and the induced/reduced expression of Toll, Toll-7 (Fig EV4B-I) and AMP genes (Fig EV5) in mutant flies after microbial infection. For example, Toll-7 was expressed at a significantly lower level in all four mutant females than in the $w^{1118}$ females after microbial infection (Fig EV4F-I), but Toll was induced in the two Toll mutant females after E. faecalis infection (Fig EV4F) and in the Toll- $7^{g 1-5} / \mathrm{CyO}$ females after P. aeruginosa (Fig EV4G) and C. albicans infection (Fig EV4H). Toll-7 was significantly up-regulated in the two Toll mutant males after $P$. aeruginosa (Fig EV4C) and C. albicans (Fig EV4D) infection and in the $T l^{I-R X A} / T M 6 B$ males after E. faecalis infection (Fig EV4B) compared with $w^{1118}$ males. Drosomycin was expressed at a significantly lower level in all four mutant flies compared with the $w^{1118}$ flies after $E$. faecalis infection (Fig EV5A and E) but was significantly up-regulated in the $\mathrm{Toll}-7^{g 1-5} / \mathrm{CyO}$ EV5D and $\mathrm{H}$ ).

\section{Discussion}


to Spz-6 as ligands for Tolls in immune signaling pathways. We report here that Spz, Spz-2

Spz-Toll-7 complexes activated drosomycin promoter, suggesting multiple Drosophila

Toll-Spz pathways in regulating the expression of antimicrobial peptide genes. truncated Toll (Toll ${ }^{\triangle \mathrm{LRR}}$ ) that has the leucine-rich repeats (LRRs) deleted is an active receptor independence of Spz ligand [40]. Among the five chimeric Tolls (Toll-2, Toll-5 to Toll-8) that activity to about $25 \%$ of that activated by Toll ${ }^{\Delta \mathrm{LRR}}$, and expression of all five chimeric Tolls and Toll ${ }^{\Delta \mathrm{LRR}}$ did not activate diptericin, defensin and cecropin promoters [16]. We expressed only the TIR domains (without the extracellular and transmembrane domains) of Toll to Toll-9 and found that expression of all nine TIRs activated drosomycin promoter to some extents, with high activity observed with TIR of Toll, followed by TIRs of Toll-7 and Toll-4. As an active 222 receptor without ligand binding, Toll ${ }^{\triangle \mathrm{LRR}}$ must be able to form dimers/oligomers. It is possible that except chimeric Toll-5, the other four chimeric Tolls (Toll-2, Toll-6 to Toll-8) could not 
225

226

228

229

230

231

232

233

234

235

236

237

238

239

240

241

242

243

244

easily form dimers/oligomers. Expression of all TIRs did not activate diptericin promoter, a result consistent with that from expression of chimeric Tolls [16].

Toll-6 and Toll-7 can function as neurotrophin receptors in the development of the central nervous system in Drosophila and may interact with Spz-2 and Spz-5, respectively [24]. We showed that Toll-7 interacted with Spz-6, but that co-expression of Toll-7 with Spz-6 did not activate the drosomycin promoter, suggesting that Toll-7-Spz-6 may play a role in development. Multiple pairs of Spz-Toll-7 in activation of drosomycin promoter as well as Toll-7 mutant male and female flies were significantly more susceptible to microbial infection suggest that Toll-7, like Toll, play roles in both innate immunity and development.

Toll-7 can recognize vesicular stomatitis virus (VSV) to induce anti-viral autophagy response [25], but it is not required for anti-VSV infection [26]. We confirmed that Toll-7 recognized VSV through binding to VSV glycoprotein. In addition, we showed that Toll also bound VSV glycoprotein, and binding of VSV to Toll and Toll-7 activated AMP gene promoters. Septic infections with different pathogens in $w^{1118}$, Toll and Toll-7 mutant flies suggest that Toll and Toll-7 differentially affect adult male and female flies in defense against infection by E. faecalis, P. aeruginosa, C. albicans and VSV. As Toll and Toll-7 both play a role in defense against microbial infection, the survival of male and female flies after septic infections depends on the overall effect of differential expression levels of Toll, Toll-7 and AMP genes. The titers of VSV-GFP (determined by the $g f p$ transcript) in $w^{1118}$, Toll and Toll-7 mutant flies maintained at the similar levels at day 1,5 and 10 post-infection in each fly line as 
245 well as among the three fly lines, indicating that Toll and Toll-7, though play roles in defense

246 against VSV infection, may not play a role in restricting VSV replication.

247 We demonstrated the existence of multiple Toll-Spz pathways in Drosophila innate

248 immunity, which raises more questions that need to be answered. What are the functions of

249 different Toll-Spz and Toll-7-Spz pairs in Drosophila immunity? How pro-Spz-2 and

250 pro-Spz-5 are processed/activated (particularly pro-Spz-2, which requires two proteolytic

251 cleavages)? Are Spz-2 and Spz-5 processed by SPE or/and other unidentified proteases?

252 What is the function of Toll-7-Spz-6? Future research will focus on answering some of these

253 questions. 


\section{Materials and Methods}

255

256

257

258

259

260

261

262

263

264

265

266

267

268

269

270

271

272

273

274

\section{Fly stocks}

Wild-type $w^{1118}$ flies were obtained from the laboratory of Dr. Leonard Dobens (School of Biological Sciences, University of Missouri - Kansas City, Missouri, USA). The Toll- $7^{g 1-5} / \mathrm{CyO}$ mutant line was a gift from Dr. Yashimasa Yagi (Division of Biological Science, Nagoya University, Nagoya, Japan), and the Toll- $7^{g l-5}$ mutant line was created by homologous recombination of an ends-in knockout system followed by hs-ICreI treatment to generate a Toll-7 knockout line with a point mutation [17]. The Toll- $7^{\text {gl-5 }}$ line was balanced over CyO to obtain the Toll- $7^{g 1-5} / \mathrm{CyO}$ mutant line, and heterozygotes were screened based on the existence of curled wings. The $T l r^{632} / T l^{I-R X A}$ and $T l^{I-R X A} / T M 6 B$ Toll (also called Toll-1) mutant lines were obtained from the laboratory of Dr. Kontoyiannis (Department of Infectious Diseases, University of Texas M. D. Anderson Cancer Center, Houston, Texas, USA) [41]. $T l r^{632} / T l^{I-R X A}$ flies were generated by crossing $T l r^{632} / T M 6 B$ and $T l^{I-R X A} / T M 6 B$ Toll-deficient flies. $T l r^{632}$ is a thermosensitive loss-of-function allele with a strong phenotype at $29^{\circ} \mathrm{C}$; thus, these flies were maintained at $29^{\circ} \mathrm{C}$ during infection. Both the $T l r^{632}$ and $T l^{I-R X A}$ mutant lines were balanced over TM6B and were recognized by multiple hair-type bristle in the upper lateral thorax/torso. The $D f(2 R) B S C 22 / S M 6 a$ line (stock \# 6647) was purchased from Bloomington Stock Center (Indiana, USA); in this line, the 56D7 - 56F12 chromosome segment was deleted by exploiting hybrid element insertion (HEI) and resolution, and this line was later balanced over SM6a to obtain flies that can be recognized by curly wings. We generated $D f(2 R) B S C 22 /$ Toll- $7^{g l-5}$ flies by crossing Toll- $7^{g 1-5} / C y O$ and $D f(2 R) B S C 22 / S M 6 a$ 
275 flies, which uncovers the Toll-7 locus to obtain Toll-7 mutants that can be screened by the

276 presence of curly wings. All the flies were cultured on corn-meal diet [42] and transferred to

277 fresh food at least $24 \mathrm{~h}$ prior to injection/infection.

\section{Gene cloning} study, we cloned Toll cDNA using the total RNA from Drosophila adult females as the template and Toll-7 cDNA using the pAC5.1-A clone, which did not contain any introns, as the template. All nine Drosophila Toll TIR domains and M. sexta Toll TIR domain [37], the ectodomains of Toll and Toll-7 and full-length Toll and Toll-7 were amplified by PCR using the forward and reverse primers listed in Table 1 and cloned into the pMT/BiP/V5-His A vector (V413020, Invitrogen) for expression of the recombinant proteins with a V5-tag at the into a modified pMT/Bip A vector [37] for expression of the recombinant Spz proteins with a

Flag-tag at the N-terminus. The PCR reactions were performed with the following conditions: 
manufacturer's instructions and digested with respective restriction enzymes, and DNA

297

298

299

300

301

302

303

304

305

306

307

308

309

310

311

312

313

314

315

316

fragments were recovered and inserted into the $\mathrm{pMT} / \mathrm{BiP} / \mathrm{V} 5-\mathrm{His} \mathrm{A}$ or modified $\mathrm{pMT} / \mathrm{Bip} \mathrm{A}$ vector using T4 DNA ligase (M0202L, NEB). The recombinant expression plasmids were then purified and sequenced in the sequencing facility at University of Missouri - Columbia for further experiments.

\section{Vesicular stomatitis virus stock culture}

Vesicular stomatitis virus (VSV) expressing green fluorescent protein (VSV-GFP), in which GFP is inserted between the 3' leader and $\mathrm{N}$ gene [43], was obtained from the laboratory of Dr. Whelan (Harvard Medical School, Boston, Massachusetts, USA) [44]. VSV-GFP was cultured and maintained in HEK293 cells in DMEM medium supplemented with 10\% heat-inactivated fetal bovine serum (\#10082063, Invitrogen) and 1\% penicillin-streptomycin solution (G6784, Sigma-Aldrich). The viral titer was measured by plaque assay using HEK293 cells [45]. For infection assays with Drosophila S2 cells, 10,000 pfu/ml VSV-GFP was used, and for the infection assays with adult flies, 10,000 pfu of VSV-GFP (in $50 \mathrm{nl}$ of PBS) were injected into each fly.

\section{Infection assays}

Drosophila adult males and females (5-7 days of age) in a batch of 20-30 flies were infected with the Gram-positive bacterium Enterococcus faecalis V583 (a gift from Dr. Michael Gilmore, Harvard Medical School, Boston, Massachusetts, USA), the Gram-negative bacterium Pseudomonas aeruginosa PA-14 (a gift from Dr. Kalai Mathee, Florida International University, Florida, USA), the fungus Candida albicans (a gift from Dr. 
317 Theodore White, School of Biological Sciences at the University of Missouri - Kansas City,

318 Missouri, USA), or VSV-GFP. Briefly, overnight bacterial and fungal cultures were diluted

319 to $\mathrm{OD}_{600}=0.2$ and $\mathrm{OD}_{600}=0.5$, respectively, washed with phosphate buffered saline (PBS,

$320 \mathrm{pH}$ 7.4) and resuspended in PBS for injection. Flies were anesthetized with $\mathrm{CO}_{2}$ (for no

321 longer than $15 \mathrm{~min}$ at a time), and $50 \mathrm{nl}$ of diluted E. faecalis V583, P. aeruginosa PA-14, C.

albicans, or VSV-GFP $(10,000 \mathrm{pfu} / 50 \mathrm{nl})$ was injected into each fly at the left intra-thoracic

region using a Drummond nanoinjector and pulled glass capillary needles. These flies were

maintained in clean bottles with fresh cornmeal diet, and the diet was changed every day

excluded from the study due to death by injury. The flies were monitored every hour (or

every day in the VSV-GFP infection assay), and the numbers of dead males and females were

recorded. The accumulation of VSV-GFP RNA in the $w^{1118}, D f(2 R) B S C 22 /$ Toll- $7^{g 1-5}$ and

$T l r^{632} / T l^{I-R X A}$ flies infected with VSV-GFP at day 1,5 and 10 post-infection was detected by real-time PCR analysis of the $g f p$ transcript using primers for GFP (Table 1).

For the infection of Drosophila S2 cells with VSV-GFP, S2 cells were grown and maintained in insect cell culture media (SH30610.02, HyClone) supplemented with 10\% heat-inactivated fetal bovine serum, $1 \%$ penicillin-streptomycin solution and $1 \%$ Gibco was cultured in HEK293 cells as described above, and the replication of VSV-GFP was detected by Western blot analysis using anti-VSV-G antibody. A stable S2 cell line 
transfected with pGL3B or the pGL3B-attacin, pGL3B-diptericin, pGL3B-drosomycin or

pGL3B-metchnikowin AMP gene promoter individually using Gencarrier-2 (\#31-00110,

340 Epoch Biolabs). Forty-eight hours after protein expression, the S2 cells were infected with

10,000 pfu/ml VSV-GFP for $24 \mathrm{~h}$ and processed for dual luciferase assay (see below).

342

343

344

345

346

347

348

349

350

351

352

353

354

355

356

357

358

\section{Transient transfection and establishment of stable S2 cell lines}

Transient transfection experiments and the establishment of stable S2 cell lines expressing full-length Toll and Toll-7 were performed as described previously [37]. For transient transfections, S2 cells were seeded overnight in complete growth medium (see above), washed with serum-free medium (SH30278.01, HyClone), and transiently transfected using GenCarrier-2 ${ }^{\mathrm{TM}}$ transfection reagent (\#31-00110, Epoch Biolabs) according to the manufacturer's instructions. DES ${ }^{\circledR}-$ Inducible/Secreted Kit with pCoBlast (K5130-01, Invitrogen) was used for the establishment of stable S2 cell lines. To select stable S2 cells expressing recombinant Toll and Toll-7, pCoBlast (Invitrogen) was co-transfected with recombinant pMT/BiP/V5-His A vectors. Forty-eight hours after transfection, S2 cells were centrifuged and resuspended in the complete growth medium containing $25 \mu \mathrm{g} / \mathrm{ml}$ Blasticidin S hydrochloride (No.15205, Sigma-Aldrich). Resistant colonies appeared one week later.

\section{Dual luciferase assays}

Dual luciferase assays were performed as described previously [46]. S2 cells were plated in 24 -well culture plates $\left(3 \times 10^{5}\right.$ cells/well $)$ overnight in the complete growth medium, washed with serum-free medium, and then transiently co-transfected with recombinant pMT/BiP/V5-His A expression plasmid (500 ng), pGL3B, pGL3B-drosomycin or 
pGL3B-diptericin firefly luciferase reporter plasmid (250 ng), or Renilla luciferase reporter plasmid (25 ng) (as an internal standard) (pRL-TK, Promega) with Gencarrier-2. After overnight transfection, serum-free medium was replaced with the complete growth medium containing copper sulfate (to a final concentration of $500 \mu \mathrm{M}$ ) for protein expression, and $36 \mathrm{~h}$ after protein expression, the firefly luciferase and Renilla luciferase activities were measured using the Dual-Luciferase Reporter Assay System (E1980, Promega) with a GloMax® Multi plasmids was used as the calibrator. These experiments were repeated at least three times (three independent biological samples or three independent cell cultures), and a representative set of data was used to prepare the figures. containing recombinant proteins were precleared with Protein G Sepharose (50\% slurry, with cell culture media were mixed with anti-Flag M2 or anti-V5 antibody (final concentration of $1 \mu \mathrm{g} / \mu \mathrm{l})$, and these mixtures were incubated at $4^{\circ} \mathrm{C}$ for $10 \mathrm{~h}$ with gentle rocking. Protein $\mathrm{G}$ Sepharose (30 $\mu \mathrm{l}$ of $50 \%$ slurry) in lysis buffer was added to the protein-antibody mixture, and 
380

381

382

384

385

386

387

388

389

390

391

392

393

394

395

396

397

398

399

400

containing immunoprecipitated proteins were collected after centrifugation, washed three times with lysis buffer, resuspended in $50 \mu \mathrm{l}$ of $1 \times$ SDS sample buffer, boiled at $95^{\circ} \mathrm{C}$ for 5 min, and used for subsequent Western blot analysis using anti-Flag M2 or anti-V5 antibody as the primary antibody as described above [46].

Co-immunoprecipitation (Co-IP) assays were also performed by mixing S2 cell culture medium containing Toll ${ }^{\text {ecto }}$ or Toll- $7^{\text {ecto }}$ proteins collected $48 \mathrm{~h}$ after protein expression with DMEM cell culture medium from VSV-GFP-infected HEK293 cells (containing VSV-GFP virions) as described above, and the interaction of Toll ${ }^{\text {ecto }}$ or Toll- $7^{\text {ecto }}$ with VSV-GFP was detected by anti-V5 or anti-VSV glycoprotein (anti-VSV-G) antibody [P5D4] (ab50549, Abcam, USA, 1:5000 dilution).

\section{Western blot analysis}

Western blot analysis of transiently transfected S2 cells or stable S2 cell lines $\left(5 \times 10^{6}\right.$ cells/well) was performed in six-well plates $48 \mathrm{~h}$ after the induction of protein expression by copper sulfate (final concentration of $250 \mu \mathrm{M}$ ). The cell culture media ( $2 \mathrm{ml}$ each) and S2 cells were collected, and the S2 cells were homogenized in $400 \mu \mathrm{l}$ of lysis buffer (50 mM Tris- $\mathrm{HCl}$, pH 7.4, $150 \mathrm{mM} \mathrm{NaCl}, 5 \mathrm{mM}$ EDTA, $1 \%$ NP-40, and $0.5 \mathrm{mM}$ PMSF) containing protease inhibitor cocktail (P8340, Sigma-Aldrich) following a previously described protocol [46]. The cell homogenates were sonicated briefly and centrifuged, and the supernatants (cell lysates) were collected. The cell culture media ( $10 \mu \mathrm{l}$ from a total volume of $2 \mathrm{ml})$ and cell lysate $(10 \mu \mathrm{l}$ from a total volume of $400 \mu$, equivalent to $\sim 5 \times 10^{4}$ cells) were separated by $8 \%, 12 \%$ or $15 \%$ SDS-PAGE, and the proteins were transferred to nitrocellulose membranes (162-0097, 
401 Bio-Rad) for Western blot analysis using anti-Flag M2 antibody (F-1804, Sigma-Aldrich,

402

403

404

405

406

407

408

409

410

411

412

413

414

415

416

417

418

419

420

421

1:5000 dilution) or anti-V5 antibody (V-8012, Sigma-Aldrich, 1:5000 dilution) as the primary antibody and alkaline phosphatase-conjugated anti-mouse antibody (A4312, Sigma-Aldrich, 1:10,000) as the secondary antibody as described previously [47]. The signal was developed using an Alkaline Phosphatase (AP)-Conjugate Color Development Kit (\#170-6432, Bio-Rad).

\section{Real-time PCR analysis}

The total RNA from flies and S2 cells was extracted, and the expression of target genes was determined by real-time PCR as described previously [37]. The flies were anesthetized on a $\mathrm{CO}_{2}$ bed, placed in 1.5-ml tubes and homogenized with disposable pestles in $1 \mathrm{ml}$ of TRIzol ${ }^{\circledR}$ Reagent (T9424, Sigma-Aldrich), and the total RNA from flies and S2 cells was extracted according to the manufacturer's instructions. The RNA pellets were air-dried and resuspended in $50 \mu 1$ of nuclease-free water, and the concentration of RNA was determined using a Nanodrop UV-Vis spectrophotometer (ND-1000, Thermo).

Total RNA (2 $\mu \mathrm{g}$ from each sample) was treated with RQ1 RNase-free DNase (M6101, Promega) to remove contaminated genomic DNA and then used for the synthesis of cDNAs in $25 \mu \mathrm{l}$ reactions using Moloney murine leukemia virus (M-MLV) reverse transcriptase (M1701, Promega) and an anchor-oligo(dT)18 primer following the manufacturer's instructions. The cDNA sample (diluted 1:50) was used as the template for quantitative real-time PCR analysis. The Drosophila ribosomal protein 49 (rp49) gene was used as an internal standard to normalize the expression of target mRNA. Real-time PCR was performed in $20 \mu \mathrm{l}$ reactions containing $10 \mu \mathrm{l}$ of $2 \times \mathrm{SYBR}{ }^{\circledR}$ GreenER ${ }^{\mathrm{TM}}$ qPCR SuperMix 
422 Universal (No. 204141, Qiagen), $4 \mu \mathrm{l}$ of $\mathrm{H}_{2} \mathrm{O}, 4 \mu \mathrm{l}$ of diluted cDNA template, and $1 \mu \mathrm{l}(10$

423 pmol) of each of the forward and reverse primers. The real-time PCR program was 2 min at

$42450^{\circ} \mathrm{C}, 10 \mathrm{~min}$ at $95^{\circ} \mathrm{C}, 40$ cycles of $95^{\circ} \mathrm{C}$ for $15 \mathrm{~s}$ and $60^{\circ} \mathrm{C}$ for $1 \mathrm{~min}$, and the dissociation

425 curve analysis. The data from three replicates of each sample were analyzed with a

426 comparative method $\left(2^{-\Delta \Delta C T}\right)$ using ABI 7500 SDS software (Applied Biosystems). The

427 baseline was automatically set by the software to maintain consistency. The cDNA sample

428 from S2 cells transfected with empty pMT/BiP/V5-His A plasmid or wild-type flies $\left(w^{1118}\right)$

429 was used as the calibrator. The expression level of target genes was calculated by the $2^{-\Delta \Delta C T}$

430 method [48], which provides the n-fold difference in relative expression compared with the

431 calibrator. All the data are presented as relative mRNA expression levels, and all the

432 experiments were repeated at least three times.

\section{Data analysis}

Three to four replicates of all the experiments were performed, and the experiments

were repeated with three to four independent biological samples. The means from a typical

dataset were used for the figures, which were prepared using GraphPad Prism (GraphPad,

San Diego, California, USA). The statistical significance of the differences was calculated by

440 significant difference $(p<0.05)$. The significance of the difference was also determined by an 


\section{Acknowledgements}

444 This work was supported by the National Natural Science Foundation of China (No.

445 31472019) and University of Missouri - Kansas City Funding for Excellence.

446

447 Author contributions

$448 \mathrm{XY}$ designed the experiments, analyzed data, interpreted results, and participated in

449 manuscript writing; MC performed most experiments, analyzed data, interpreted results, and

450 participated in manuscript writing; CL performed some experiments and analyzed data; $\mathrm{ZH}$

451 and YL helped perform some experiments; XL and YW participated in manuscript writing;

452 YI and MS helped interpret results and participated in manuscript writing.

453

\section{Conflict of interest}

455 The authors declare that they have no conflict of interest. 


\section{References:}

1. Hergannan JA, Rechhart JV (1997) Drosophila immunity. Trends Cell Biol 7: 309-316

2. Yi H, Chowdhury M, Huang Y-D, Yu X-Q (2014) Insect antimicrobial peptides and their applications. Appl Microbiol Biotechnol 98: 5807-22.

3. Lemaitre B, Nicolas E, Michaut L, Reichhart JM, Hoffmann JA (1996) The dorsoventral regulatory gene cassette spatzle/Toll/cactus controls the potent antifungal response in Drosophila adults. Cell 86: $973-983$

4. Anderson KV, Jurgens G, Nusslein-Volhard C (1985) Establishment of dorsal-ventral polarity in the Drosophila embryo: genetic studies on the role of the Toll gene product. Cell 42: 779-789

5. Leulier F, Lemaitre B (2008) Toll-like receptors--taking an evolutionary approach. Nat Rev Genet 9: 165-178

6. Akira S, Uematsu S, Takeuchi O (2006) Pathogen recognition and innate immunity. Cell 124: $783-801$

7. Chao W (2009) Toll-like receptor signaling: a critical modulator of cell survival and ischemic injury in the heart. Am J Physiol Heart Circ Physiol 296: H1-12

8. Li X, Jiang S, Tapping RI (2010) Toll-like receptor signaling in cell proliferation and survival. Cytokine 49: 1-9

9. Rock FL, Hardiman G, Timans JC, Kastelein RA, Bazan JF (1998) A family of human receptors structurally related to Drosophila Toll. Proc Natl Acad Sci USA 95: 588-593

10. Jin MS, Lee J-O (2008) Structures of TLR-ligand complexes. Curr Opin Immunol 20: 414-419

11. Morisato D, Anderson KV (1994) The spätzle gene encodes a component of the extracellular signaling pathway establishing the dorsal-ventral pattern of the Drosophila embryo. Cell 76: 677-88.

12. Weber AN, Tauszig-Delamasure S, Hoffmann JA, Lelievre E, Gascan H, Ray KP, Morse MA, Imler JL, Gay NJ (2003) Binding of the Drosophila cytokine Spatzle to Toll is direct and establishes signaling. Nat Immunol 4: 794-800

13. Takeuchi O, Akira S (2010) Pattern recognition receptors and inflammation. Cell 140: 805-820

14. Kawai T, Akira S (2006) TLR signaling. Cell Death Differ 13: 816-825

15. Bilak H, Tauszig-Delamasure S, Imler JL (2003) Toll and Toll-like receptors in Drosophila. Biochem Soc Trans 31: 648-651

16. Tauszig S, Jouanguy E, Hoffmann JA, Imler J-L (2000) Toll-related receptors and the control of antimicrobial peptide expression in Drosophila. Proc Natl Acad Sci USA 97: 10520-10525

17. Yagi Y, Nishida Y, Ip YT (2010) Functional analysis of Toll-related genes in Drosophila. Dev Growth Differ 52: 771-783

18. Parker JS, Mizuguchi K, Gay NJ (2001) A family of proteins related to Spatzle, the toll receptor ligand, are encoded in the Drosophila genome. Proteins 45: 71-80

19. Ligoxygakis P, Bulet P, Reichhart JM (2002) Critical evaluation of the role of the Toll-like receptor 18-Wheeler in the host defense of Drosophila. EMBO Rep 3: 666-673 
20. Williams MJ, Rodriguez A, Kimbrell DA, Eldon ED (1997) The 18-wheeler mutation reveals complex antibacterial gene regulation in Drosophila host defense. EMBO J 16: 6120-6130

21. Akhouayri I, Turc C, Royet J, Charroux B (2011) Toll-8/Tollo negatively regulates antimicrobial response in the Drosophila respiratory epithelium. PLoS Pathog 7: e1002319

22. Bettencourt R, Tanji T, Yagi Y, Ip YT (2004) Toll and Toll-9 in Drosophila innate immune response. J Endotoxin Res 10: 261-268

23. Ooi JY, Yagi Y, Hu X, Ip YT (2002) The Drosophila Toll-9 activates a constitutive antimicrobial defense. EMBO Rep 3: 82-87

24. McIlroy G, Foldi I, Aurikko J, Wentzell JS, Lim MA, Fenton JC, Gay NJ, Hidalgo A (2013) Toll-6 and Toll-7 function as neurotrophin receptors in the Drosophila melanogaster CNS. Nat Neurosci 16: 1248-1256

25. Nakamoto M, Moy RH, Xu J, Bambina S, Yasunaga A, Shelly SS, Gold B, Cherry S (2012) Virus recognition by Toll-7 activates antiviral autophagy in Drosophila. Immunity 36: $658-667$

26. Lamiable O, Arnold J, de Faria IJ, Olmo RP, Bergami F, Meignin C, Hoffmann JA, Marques JT, Imler JL (2016) Analysis of the contribution of hemocytes and autophagy to Drosophila antiviral immunity. J Virol 90: 5415-5426

27. Imler JL, Hoffmann JA (2000) Signaling mechanisms in the antimicrobial host defense of Drosophila. Curr Opin Microbiol 3: 16-22

28. Meng X, Khanuja BS, Ip YT (1999) Toll receptor-mediated Drosophila immune response requires Dif, an NF-kappaB factor. Genes Dev 13: 792-797

29. Rutschmann S, Jung AC, Hetru C, Reichhart JM, Hoffmann JA, Ferrandon D (2000) The Rel protein DIF mediates the antifungal but not the antibacterial host defense in Drosophila. Immunity 12: 569-580

30. DeLotto Y, DeLotto R (1998) Proteolytic processing of the Drosophila Spatzle protein by easter generates a dimeric NGF-like molecule with ventralising activity. Mech Dev 72: 141-148

31. Levashina EA, Langley E, Green C, Gubb D, Ashburner M, Hoffmann JA, Reichhart J-M (1999) Constitutive activation of Toll-mediated antifungal defense in Serpin-deficient Drosophila. Science 285: 1917-1919

32. Jang IH, Chosa N, Kim SH, Nam HJ, Lemaitre B, Ochiai M, Kambris Z, Brun S, Hashimoto C, Ashida M, et al. (2006) A Spatzle-processing enzyme required for toll signaling activation in Drosophila innate immunity. Dev Cell 10: 45-55

33. Hu X, Yagi Y, Tanji T, Zhou S, Ip YT (2004) Multimerization and interaction of Toll and Spätzle in Drosophila. Proc Natl Acad Sci USA 101: 9369-9374

34. Parthier C, Stelter M, Ursel C, Fandrich U, Lilie H, Breithaupt C, Stubbs MT (2014) Structure of the Toll-Spatzle complex, a molecular hub in Drosophila development and innate immunity. Proc Natl Acad Sci USA 111: 6281-6286

35. Horng T, Medzhitov R (2001) Drosophila MyD88 is an adapter in the Toll signaling pathway. Proc Natl Acad Sci USA 98: 12654-12658 
36. Tauszig-Delamasure S, Bilak H, Capovilla M, Hoffmann JA, Imler JL (2002) Drosophila MyD88 is required for the response to fungal and Gram-positive bacterial infections. Nat Immunol 3: 91-97

37. Zhong X, Xu XX, Yi HY, Lin C, Yu XQ (2012) A Toll-Spätzle pathway in the Tobacco Hornworm, Manduca sexta. Insect Biochem Mol Biol 42: 514-524

38. Luo C, Shen B, Manley JL, Zheng L (2001) Tehao functions in the Toll pathway in Drosophila melanogaster: possible roles in development and innate immunity. Insect Mol Biol 10: 457-464

39. Narbonne-Reveau K, Charroux B, Royet J (2011) Lack of an antibacterial response defect in Drosophila Toll-9 mutant. PLoS One 6: e17470

40. Winans KA, Hashimoto C (1995) Ventralization of the Drosophila embryo by deletion of extracellular leucine-rich repeats in the Toll protein. Mol Biol Cell 6: 587-596

41. Lionakis MS, Kontoyiannis DP (2012) Drosophila melanogaster as a model organism for invasive aspergillosis. Methods Mol Biol 845: 455-468

42. Moy RH, Gold B, Molleston JM, Schad V, Yanger K, Salzano MV, Yagi Y, Fitzgerald KA, Stanger BZ, Soldan SS, Cherry S (2014) Antiviral autophagy restricts Rift Valley fever virus infection and is conserved from flies to mammals. Immunity 40: 51-65

43. Schott DH, Cureton DK, Whelan SP, Hunter CP (2005) An antiviral role for the RNA interference machinery in Caenorhabditis elegans. Proc Natl Acad Sci USA 102: 18420-18424

44. Heinrich BS, Cureton DK, Rahmeh AA, Whelan SPJ (2010) Protein expression redirects Vesicular Stomatitis Virus RNA synthesis to cytoplasmic inclusions. PLoS Pathog 6: e1000958

45. Baer A, Kehn-Hall K (2014) Viral concentration determination through plaque assays: using traditional and novel overlay systems. J Vis Exp 93: e52065

46. Zhong X, Chowdhury M, Li CF, Yu XQ (2017) Transcription factor Forkhead regulates expression of antimicrobial peptides in the Tobacco Hornworm, Manduca sexta. Sci Rep 7: 2688

47. Zhong X, Rao XJ, Yi HY, Lin XY, Huang XH, Yu XQ (2016) Co-expression of Dorsal and Rel2 negatively regulates antimicrobial peptide expression in the Tobacco Hornworm Manduca sexta. Sci Rep 6: 20654

48. Livak KJ, Schmittgen TD (2001) Analysis of relative gene expression data using real-time quantitative PCR and the 2(-Delta Delta C(T)) Method. Methods 25: 402-408 


\section{Figure legends}

574 Figure 1 - Activation of the drosomycin promoter through the overexpression of TIR

575 domains.

576 A, B Expression of V5-tagged TIR domains from Drosophila Toll to Toll-9 and M. sexta

577 Toll in S2 cells detected by anti-V5 antibody.

578 C Relative luciferase activity of drosomycin and diptericin promoter reporters in S2 cells

579 overexpressing TIR domains.

580 Data information: In $\mathrm{C}$, the graph shows mean $\pm \mathrm{SEM}, \mathrm{n}=3$; identical letters show a 581 non-significant difference $(p>0.05)$, whereas different letters indicate a significant difference $(p<0.05)$, one-way ANOVA followed by Tukey's multiple comparison test.

Figure 2 - Interaction of Toll and Toll-7 ectodomains with Spz proteins.

585 Recombinant V5-tagged ectodomains of Toll and Toll-7 (Toll ${ }^{\text {ecto }}$ and Toll- $7^{\text {ecto }}$ ) and the

586 Flag-tagged active cystine knot domains of Spz to Spz-6 were overexpressed in S2 cells 587 separately, and cell lysates from Toll ${ }^{\text {ecto }}$ (or Toll- $7^{\text {ecto }}$ ) and one of the six Spz proteins were 588 mixed for co-immunoprecipitation (Co-IP) assays. Lanes 1-6 were Spz to Spz-6 mixed with 589 Toll ${ }^{\text {ecto }}$ or Toll- $7^{\text {ecto }}$.

590 A, E Anti-V5 antibody precipitated Toll ${ }^{\text {ecto }}$ (A) and Toll- $7^{\text {ecto }}$ (E) proteins, and these were 591 detected with anti-V5 monoclonal antibody.

B, F Spz proteins co-immunoprecipitated with Toll ${ }^{\text {ecto }}$ (B) and Toll- $7^{\text {ecto }}$ (F) and were detected 

antibody.

596

D, H Toll ${ }^{\text {ecto }}(\mathrm{D})$ and Toll- $7^{\text {ecto }}(\mathrm{H})$ co-immunoprecipitated with Spz proteins and were detected with anti-V5 antibody.

598

599

Figure 3 - Activation of the drosomycin promoter by multiple pairs of Toll-Spz and

600

\section{Toll-7-Spz.}

601

A-C The relative luciferase activity of the drosomycin or diptericin promoter reporter in S2

602 cells overexpressing full-length Toll and one of the six Spz proteins (A), overexpressing Toll-7 with one of the six Spz proteins (B), or overexpressing individual Toll or Spz proteins or different pairs of Toll and Spz proteins (C) was determined using a Dual-Luciferase® Reporter Assay System.

606

Data information: In (A-C), the graphs show mean \pm SEM, $n=3$; identical letters show a non-significant difference $(p>0.05)$, whereas different letters indicate a significant difference $(p<0.05)$, one-way ANOVA followed by Tukey's multiple comparison test. gene promoters by VSV infection.

612 A Expression of Toll ${ }^{\text {ecto }}$ (lane-1) and Toll- $7^{\text {ecto }}$ (lane-2) in S2 cell culture media detected by anti-V5 antibody, and detection of VSV glycoprotein (VSV-G) (lane 3) in the VSV-infected cell culture media with anti-VSV-G antibody. 
615 B, C Interaction of Toll ${ }^{\text {ecto }}$ and Toll- $7^{\text {ecto }}$ with VSV-G. V5-tagged Toll ${ }^{\text {ecto }}$ and Toll-7 $7^{\text {ecto }}$ were 616 mixed with VSV virions, and proteins were pulled down with anti-V5 antibody. 617 Immunoprecipitated Toll ${ }^{\text {ecto }}$ (lane-1) and Toll-7 $7^{\text {ecto }}$ (lane-2) were detected with anti-V5 618 antibody (B), and co-immunoprecipitated VSV-G protein was detected with anti-VSV-G 619 antibody (C).

620 D, E Activation of AMP gene promoter reporters in Toll and Toll-7 cell lines by VSV 621 infection. Stable S2 cell lines expressing recombinant full-length Toll and Toll-7 were 622 transfected with AMP gene promoter reporters and then infected with VSV. The relative 623 luciferase activity was determined using a Dual-Luciferase ${ }^{\circledR}$ Reporter Assay System.

624 Data information: In (D, E), the graphs show mean $\pm \mathrm{SEM}, \mathrm{n}=3$; *** $p<0.001$, unpaired t-test.

Figure 5 - Toll and Toll-7 confer resistance to microbial infection in adult flies.

627 A-H $w^{1118}, T$ Toll- $7^{g 1-5} / C y O, D f(2 R) B S C 22 / T o l l-7^{g 1-5}, T 1^{I-R X A} / T M 6 B$ and $T l r^{632} / T l^{I-R X A}$ mutant males (A-D) and females (E-H) were infected with E. faecalis, P. aeruginosa, C. albicans and 629 VSV-GFP, and the cumulative survival of the flies was recorded.

630 Data information: In (A-H), ${ }^{*} p<0.05, * * p<0.01$ and $* * * p<0.001$; 'ns' for not significant 631 difference when compared with $w^{1118}$, unpaired t-test. 
633

\begin{tabular}{|c|c|c|c|}
\hline For cloning & Forward Primers $\left(5^{\prime} \rightarrow 3^{\prime}\right)$ & Names & Reverse Primers $\left(5^{\prime} \rightarrow 3^{\prime}\right)$ \\
\hline DmToll-KpnI-N & ATGGTACCAATGAGTCGACTAAAGGCC & DmToll-ApaI-C & ATGGGCCCTACGTCGCTCTGTTTGGC \\
\hline DmToll-7-KpnI-N & CGGGGTACCAATGGCGGCAATCCTGCTGCT & DmToll-7-NotI-C & GAATGCGGCCGCTTCACCAGATACGCCTGAACAT \\
\hline DmToll-KpnI-N & ATGGTACCAATGAGTCGACTAAAGGCC & DmToll $^{\text {ecto }}$-ApaI-C & ATGGGCCCGAACACGCCCTTTTCCGCCGG \\
\hline DmToll-7-KpnI-N & CGGGGTACCAATGGCGGCAATCCTGCTGCT & DmToll- - $^{\text {ecto }}$-NotI-C & GAATGCGGCCGCTTATACGATTCTGGGATACCATGCT \\
\hline MsTIR-KpnI-N & ATGGTACCACCGTACGACGCGTTTGTGTCTTTCGCACA & MsTIR-ApaI-C & ATGGGCCCTTTGTAGCAAGGACTCGCGCCCGGCGCTGG \\
\hline DmTIR-KpnI-N & ATGGTACCAAAGTTCGATGCCTTCATCTCG & DmTIR-ApaI-C & ATGGGCCCTACGTCGCTCTGTTTGGCA \\
\hline DmTIR-2-SpeI-N & CTGGACTAGTATGATCATCCTGCACTCGGAGAA & DmTIR-2-NotI-C & GAATGCGGCCGCTTGACCAGGAAAGCTTGGCCGTT \\
\hline DmTIR-3-SpeI-N & CTGGACTAGTATGAGGTTCGATGCCTTTCTGGC & DmTIR-3-NotI-C & GAATGCGGCCGCTTGTCAACGTAGCTTGGTAGTAG \\
\hline DmTIR-4-SpeI-N & CTGGACTAGTATGAAATACGATGCATTCCTATC & DmTIR-4-ApaI-C & AATGGGCCCTACCTTTGTTTCTGCATCTGA \\
\hline DmTIR-5-SpeI-N & CTGGACTAGTATGACCTACGATGCCTTCATCTC & DmTIR-5-NotI-C & GAATGCGGCCGCTTGATTAGCGGCCCCGCATGCTT \\
\hline DmTIR-6-SpeI-N & CTGGACTAGTATGGATGCCTACTTCGCCTACAG & DmTIR-6-NotI-C & GAATGCGGCCGCTTCGCCCACAGGTTCTTCTGCTGA \\
\hline DmTIR-7-SpeI-N & CTGGACTAGTATGGTGCTCCTGCATTCCGCCAA & DmTIR-7-NotI-C & GAATGCGGCCGCTTCACCAGATACGCCTGAACAT \\
\hline DmTIR-8-SpeI-N & CTGGACTAGTATGTTCGACGCCTTCGTTTCGTA & DmTIR-8-NotI-C & GAATGCGGCCGCTTCATGTGCAGATTTCTAGACG \\
\hline DmTIR-9-SpeI-N & CTGGACTAGTATGTTCATCAGCTACTGCCAGAA & DmTIR-9-ApaI-C & AATGGGCCCAACACTGATCTCTCTGGAGT \\
\hline DmSpz-KpnI-N & $\begin{array}{l}\text { ATGGTACCCATGGACTACAAGGACGACGATGACAAGGC } \\
\text { GGCCGCTGTTGGTGGCTCAGACGA }\end{array}$ & DmSpz-PmeI-C & CGGTTTAAACTCACCCAGTCTTCAACGC \\
\hline DmSpz-2-KpnI-N & GAATGCGGCCGCTCTCGATGCCTGCGAGTCGAAG & DmSpz-2-PmeI-C & CGGTTTAAACCTAGCGATAACCATCCACTTGGC \\
\hline DmSpz-3-KpnI-N & GAATGCGGCCGCTCTCGATGCCTGCGAGTCGAAG & DmSpz-3-PmeI-C & CGGTTTAAACCTAGGGATTACATCTACAGA \\
\hline DmSpz-4-KpnI-N & GAATGCGGCCGCTGGAGTAAATGCCTGTCCCGT & DmSpz-4-PmeI-C & CTTTTTAAACTTAGTCCTCCAAGAAATCGA \\
\hline DmSpz-5-KpnI-N & GAATGCGGCCGCTCAAAGTCCGGGGCGCTCCAC & DmSpz-5-PmeI-C & CGGTTTAAACTTAATTGGCGGCTATCGTGC \\
\hline DmSpz-6-KpnI-N & GAATGCGGCCGCTTGTCACTACCTGGACGGCGG & DmSpz-6-KpnI-C & CGGTTTAAACTCACAACTCGGCCACCGACT \\
\hline pGL3B-Dpt-N & GGGGTACCAGTAACTTTACTGATAAGACTTGGATTCTC & pGL3B-Dpt-C & GAAGATCTCTCAGTTGTTCTCAATTGAAGAACTG \\
\hline pGL3B-Drs-N & GGGGTACCCAATGAAAGTGATAATACGAATTGACC & pGL3B-Drs-C & GAAGATCTATTGGAAAAGGTTCTCACGGAGC \\
\hline pGL3B-Att-N & GGGGTACCATACTTGCTCAAAACAAAACCACA & pGL3B-Att-C & GAAGATCTGTTGCTGAACTGGATTGCTGG \\
\hline pGL3B-Met-N & CGGGGTACCTTTCTTAGCCCAGTTCTTAGTTCTG & pGL3B-Met-C & GGAAGATCTCTTAGCTCGGTGGCGGGAATTGATTG \\
\hline For qPCR & Forward Primers (5'-3') & Names & Reverse Primers (5'-3') \\
\hline DmDpt-N & ATGACCATGAAGCCCACTCC & DmDpt-C & ATTCAGTCCAATCTCCGGGC \\
\hline DmDrs-N & TACTTGTTCGCCCTCTTCGC & DmDrs-C & GGAGCGTCCCTCCTCCTTGC \\
\hline DmRp49-N & GCCCAAGGGTATCGACAACA & DmRp49-C & ACCTCCAGCTCGCGCACGTT \\
\hline DmToll-N & TCCAGACCCAGATCAACTCC & DmToll-C & TAGCCCAGCGAGCTAATGTT \\
\hline DmToll-7-N & AGTTCGAGTGCGAGTGCC & DmToll-7-C & TTGCATTGTTCGCTGGCG \\
\hline VSV-GFP-N & TTTTCTGTCAGTGGAGAGGGT & VSV-GFP-C & ATCTGGGTATCTCGCAAAGCA \\
\hline
\end{tabular}




\section{Expanded View Figure legends}

635

636

637

638

639

640

641

642

643

644

645

646

647

648

649

650

651

652

653

654

655

656

Figure EV1 - Amino acid sequences of Drosophila pro-Spätzle and cistine knot Spätzle proteins, and multiple sequence alignment of Drosophila Spz, Spz-2 and Spz-5.

A The amino acid sequences of pro-Spz to pro-Spz-6 were obtained from the NCBI website (https://www.ncbi.nlm.nih.gov/) with the indicated accession numbers. The predicted cistine knot Spz domains were underlined.

B Drosophila cistine knot Spz, Spz-2 and Spz-5 domains (from Fig EV1A above) were aligned by Clustal Omega (https://www.ebi.ac.uk/Tools/msa/clustalo/). Identical residues are indicated by “*”, highly conserved residues are indicated by “:”, and conserved residues are indicated by ".".

\section{Figure EV2 - Expression of recombinant Toll, Toll-7 and six Spz proteins in S2 cells.}

A-D V5-tagged recombinant Toll, Toll-7, Toll ${ }^{\text {ecto }}$ and Toll- $7^{\text {ecto }}$ as well as Flag-tagged active cistine knot Spz to Spz-6 proteins were expressed in S2 cells. Proteins in the cell culture media (A and $\mathrm{B}$ ) and the cell lysates (C and D) were detected by anti-V5 (A and C) or anti-Flag (B and D) monoclonal antibody.

Figure EV3 - Expression of $g f p$ transcript in the flies infected with VSV-GFP.

A, B $w^{1118}, D f(2 R) B S C 22 / T o l l-7^{g l-5}$ and $T l r^{632} / T l^{I-R X A}$ male and female flies were infected with VSV-GFP, and flies at 1, 5 and 10 days post-infection were collected for preparation of total RNAs. Replication of VSV-GFP in the flies was determined by expression of $g f p$ transcript in the RNA samples by real-time PCR using Drosophila ribosomal protein 49 (rp49) gene as an internal standard, and relative expression of $g f p$ in $w^{1118}$ males (A) or females (B) was arbitrarily set as 1 . 
657 No significant difference in the expression level of $g f p$ among $w^{1118}$, Df/Toll- $7^{g 1-5}$ and $658 T r^{632} / T l^{I-R X A}$ males (A) and female (B) was observed at days 1, 5 and 10 post-infection, and no 659 significant difference in $g f p$ expression level was observed in $w^{1118}$, Df/Toll- $7^{g 1-5}$ or $T l r^{632} / T l^{I-R X A}$ 660 flies between days 1, 5 and 10 post-infection.

661 Data information: In (A, B), graphs show mean \pm SEM, $n=3$.

662

663 Figure EV4 - Expression of Toll and Toll-7 transcripts in $w^{1118}$ and mutant flies after E. 664 faecalis, $P$. aeruginosa, $C$. albicans, and VSV-GFP infection.

665 A Expression of Toll and Toll-7 transcripts in the un-infected $w^{1118}$ males and females. Real-time 666 PCRs were performed using Drosophila ribosomal protein 49 (rp49) gene as an internal standard, 667 and expression of Toll in $w^{1118}$ males was arbitrarily set as 1.

668 B-I Expression of Toll and Toll-7 transcripts in $w^{1118}$, Toll- $7^{g 1-5} / C y O, D f(2 R) B S C 22 / T o l l-7^{g 1-5}$, $669 T I^{I-R X A} / T M 6 B$ and $T l r^{632} / T l^{I-R X A}$ mutant males (B-E) and females (F-I) after E. faecalis, P. 670 aeruginosa, C. albicans and VSV-GFP infection. Real-time PCRs were performed using 671 Drosophila rp49 gene as an internal standard and expression of Toll or Toll-7 mRNA in $w^{1118}$ flies 672 after infection was arbitrarily set as 1.

673 Data Information: In (A-I), graphs show mean \pm SEM, n=3; identical letters are not significant 674 difference $(p>0.05)$, whereas different letters indicate significant difference $(p<0.05)$, one-way 675 ANOVA followed by Tukey's multiple comparison test; * $p<0.05$, ** $p<0.01$ and *** $p<$ $676 \quad 0.001$, unpaired t-test. 
677 Figure EV5 - Expression of drosomycin and diptericin transcripts in $w^{1118}$ and mutant flies 678 after $E$. faecalis, $P$. aeruginosa, $C$. albicans, and VSV-GFP infection.

679 A-H Expression of drosomycin (Drs) and diptericin (Dpt) transcripts in $w^{1118}$, Toll- $7^{g 1-5} / C y O$, $680 D f(2 R) B S C 22 / T o l l-7^{g 1-5}, T 1^{I-R X A} / T M 6 B$ and $T l r^{632} / T l^{I-R X A}$ mutant males (A-D) and females (E-H) 681 after E. faecalis, P. aeruginosa, C. albicans and VSV-GFP infection. Real-time PCRs were 682 performed using Drosophila rp49 gene as an internal standard and expression of Drs or Dpt in $683 w^{1118}$ flies after infection was arbitrarily set as 1.

684 Data information: In $(A-H)$, graphs show mean \pm SEM, $n=3$; identical letters are not significant 685 difference $(p>0.05)$, whereas different letters indicate significant difference $(p<0.05)$, one-way 686 ANOVA followed by Tukey's multiple comparison test. 

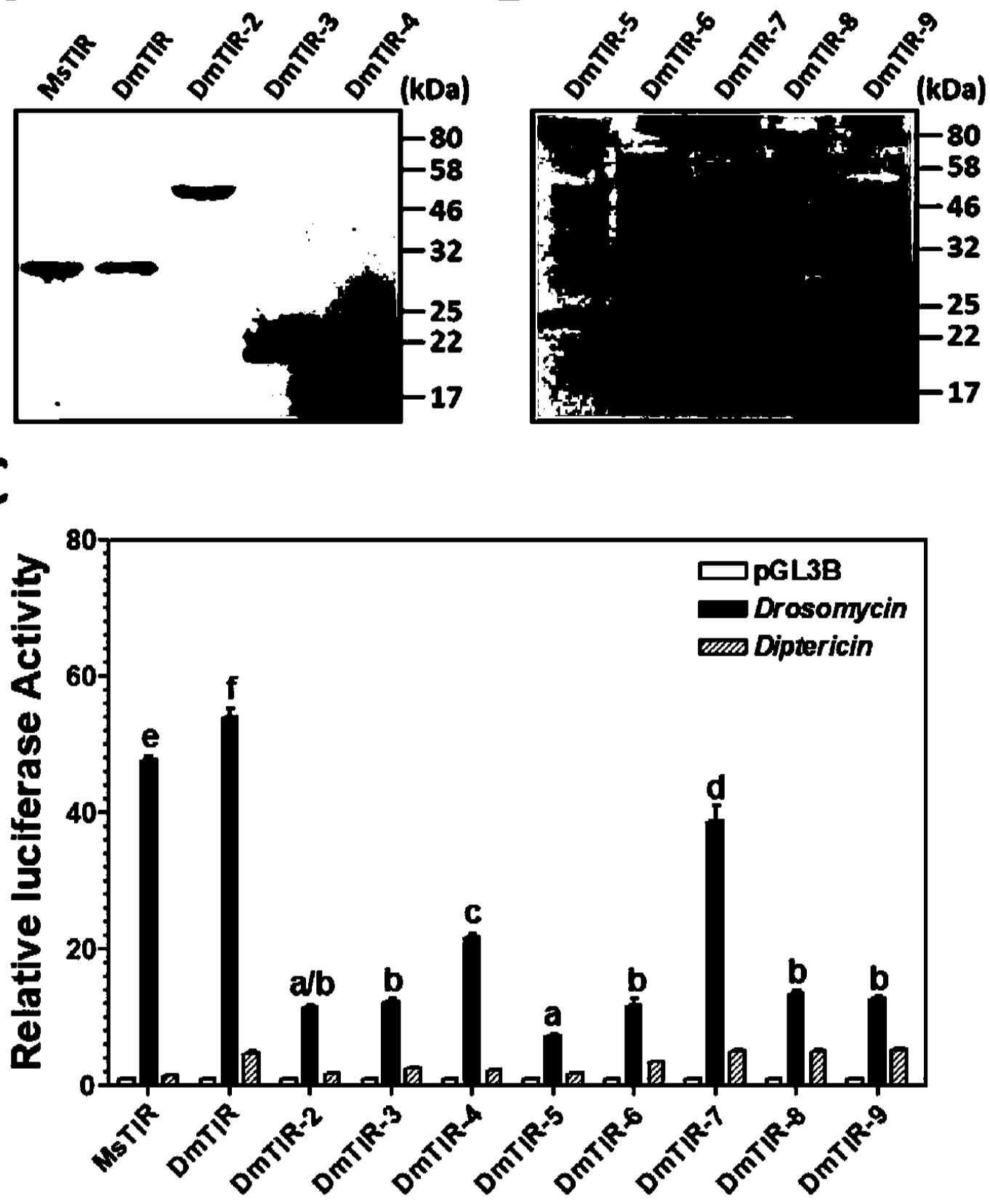

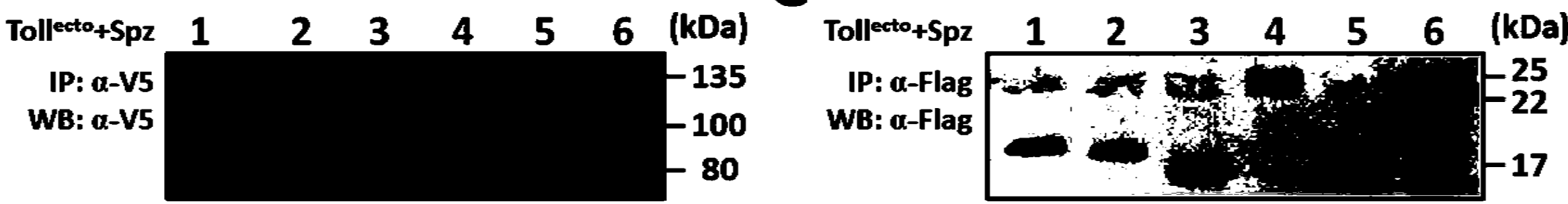

B

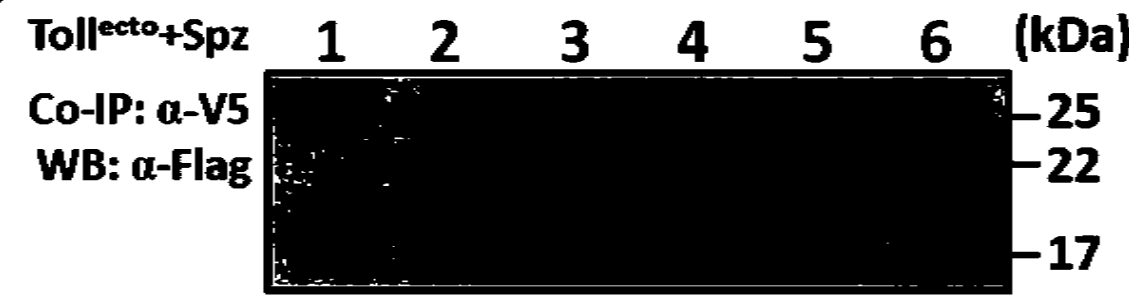

D

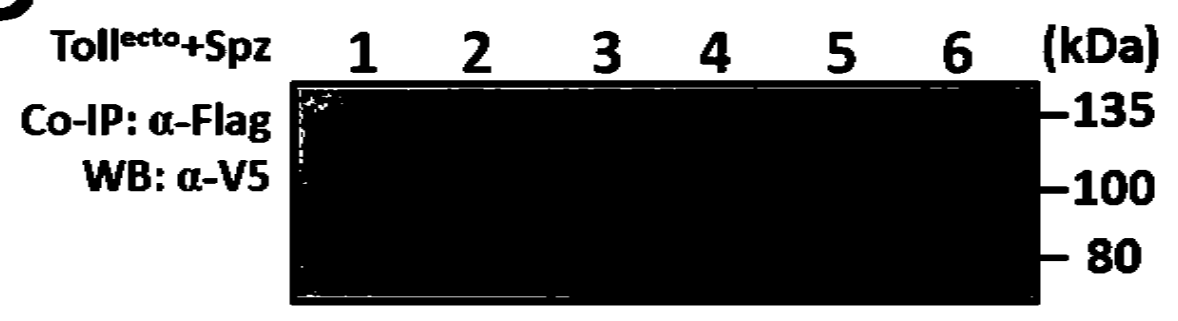

E

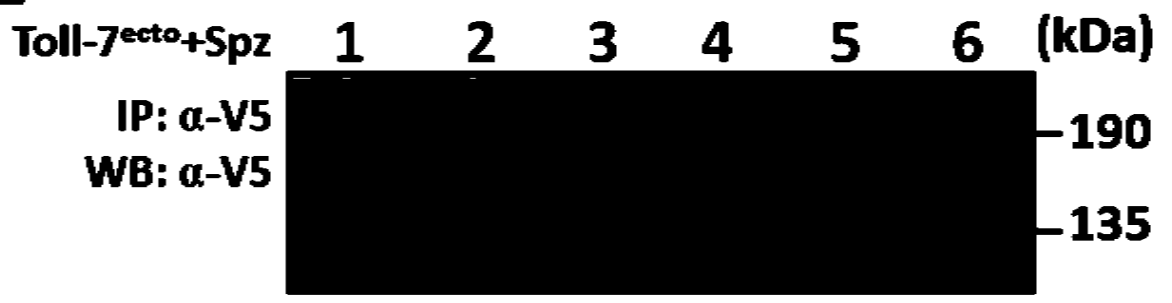

$G$

5

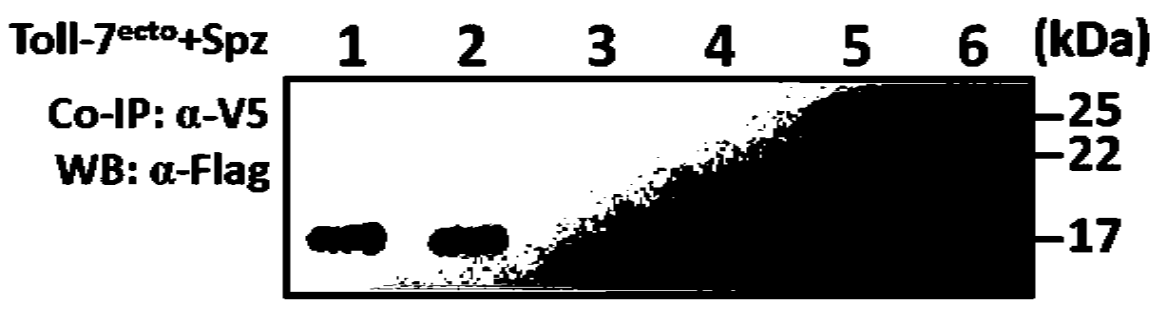

$\pi$

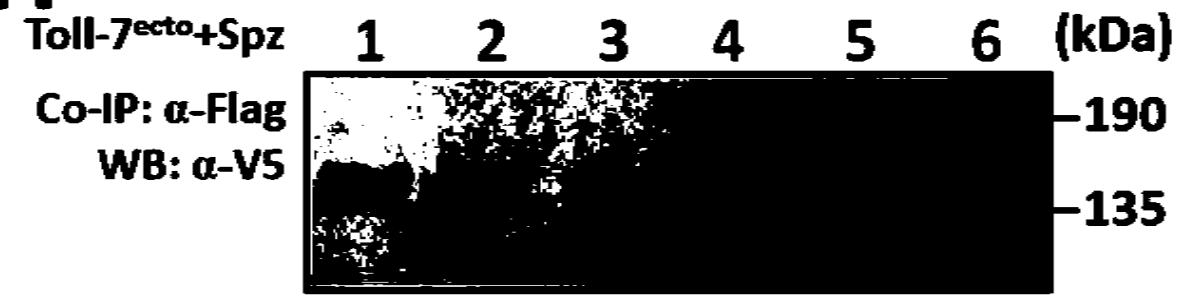



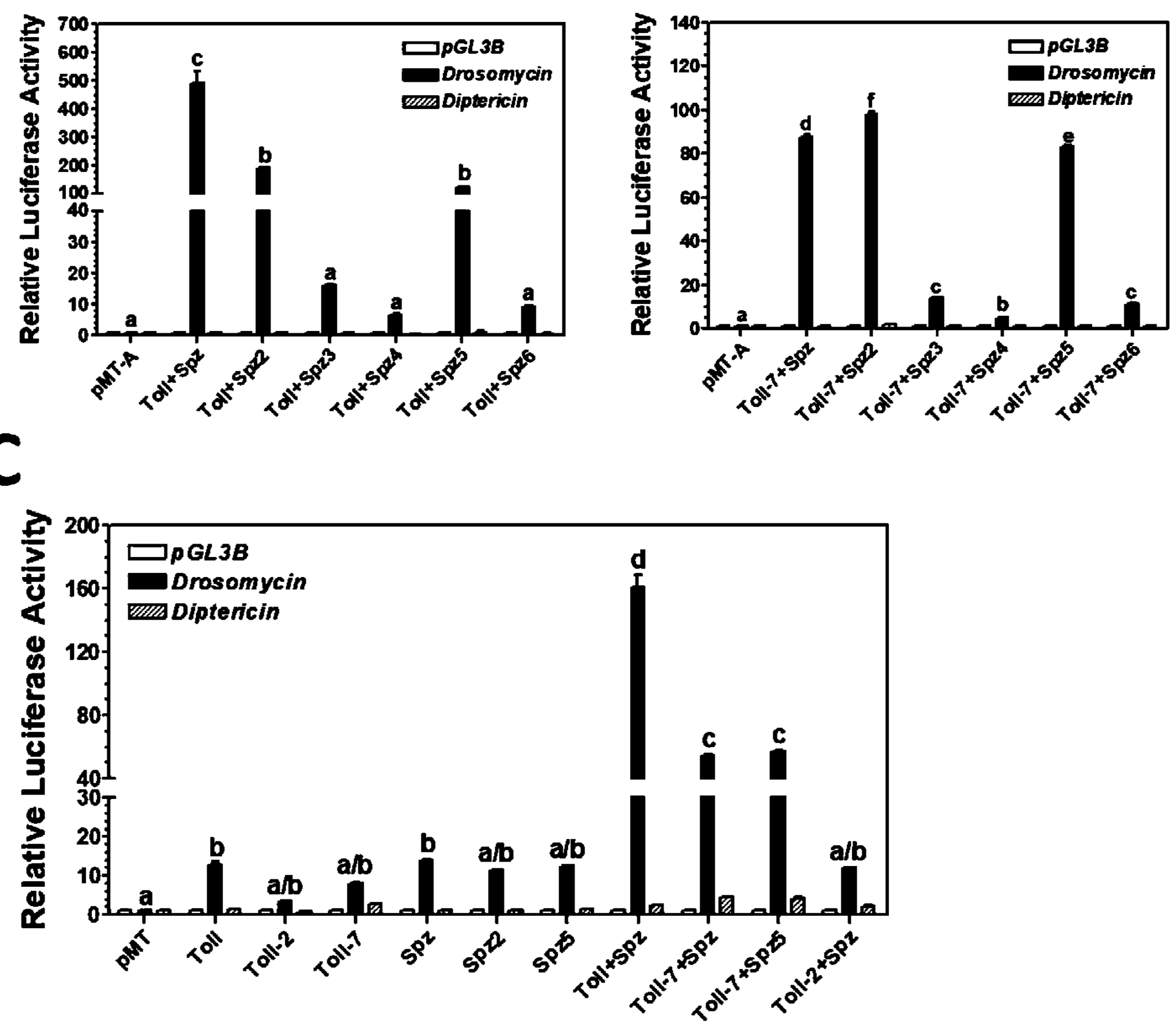


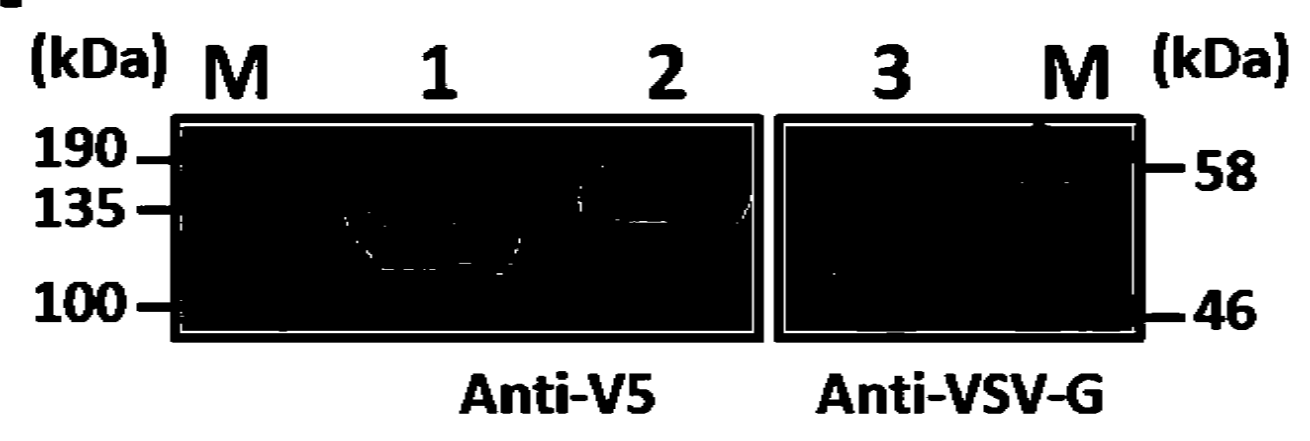

B

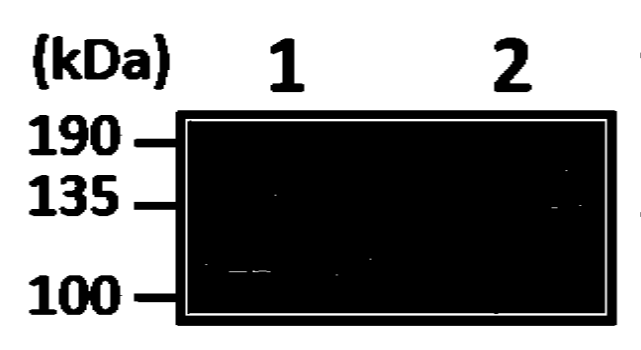

Tollecto+VSV

IP: $\alpha-\mathbf{V}$

WB: $a-\mathbf{V}$

(kDa) 12 Tollecto+VSV

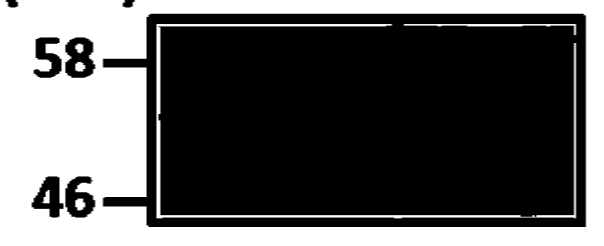

Co-IP: a-V5

WB: $a-V S V-G$

E
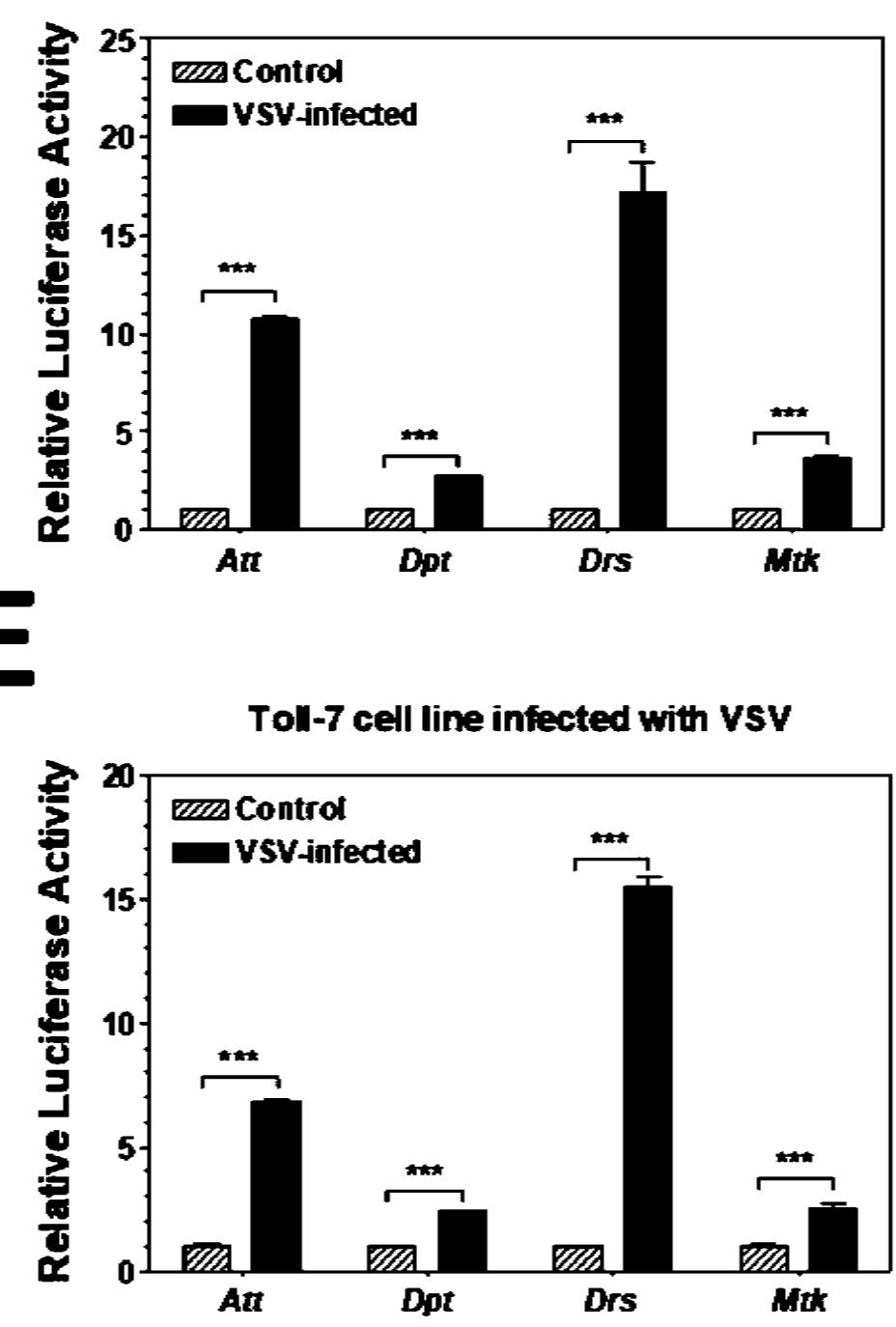
A

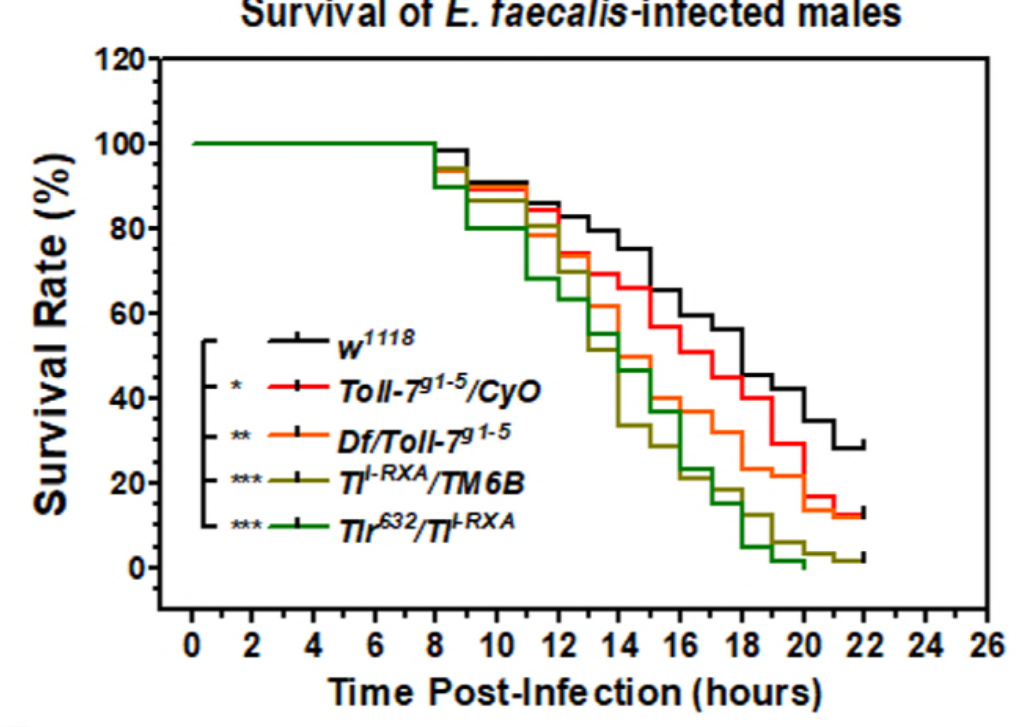

Survival of C. albicans-infected males

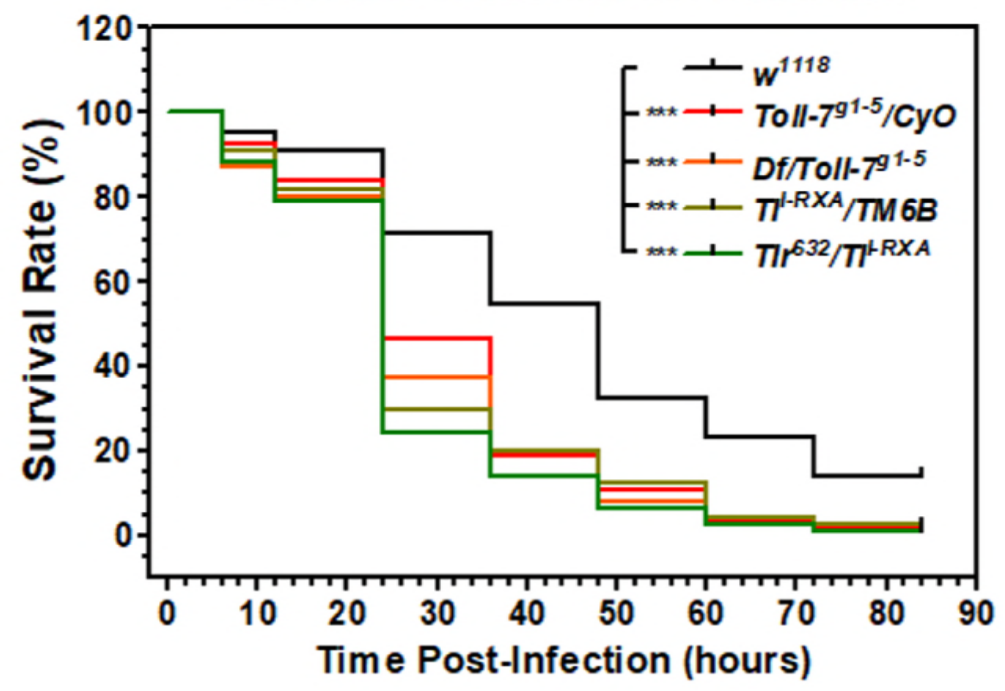

Survival of $P$. aeruginosa-infected males

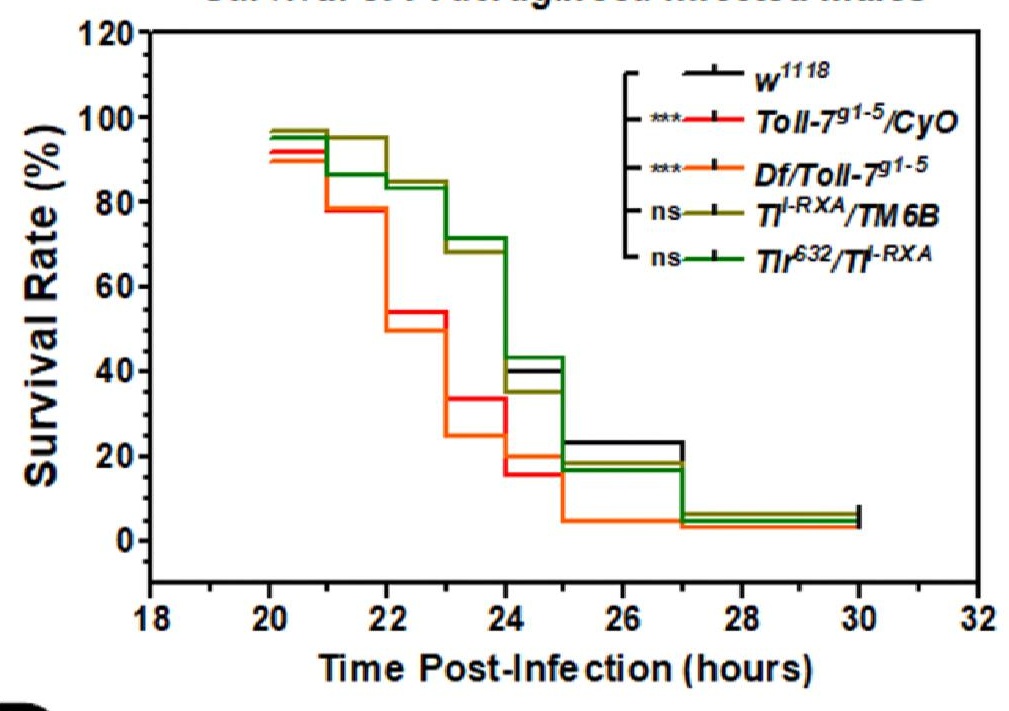

Survival of VSV-infected males

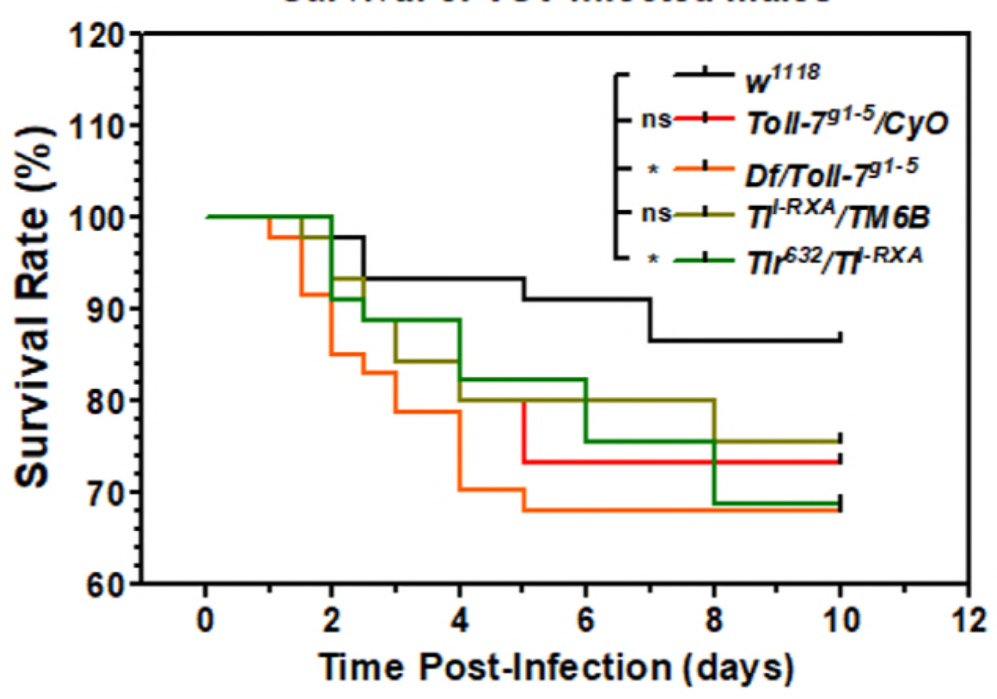




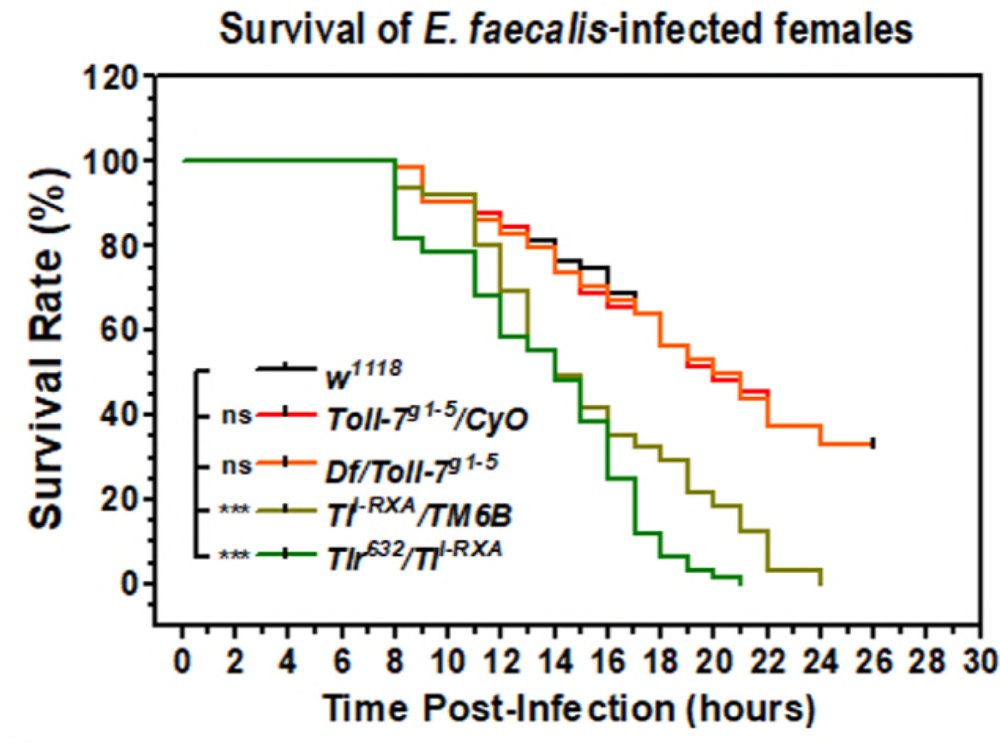

G

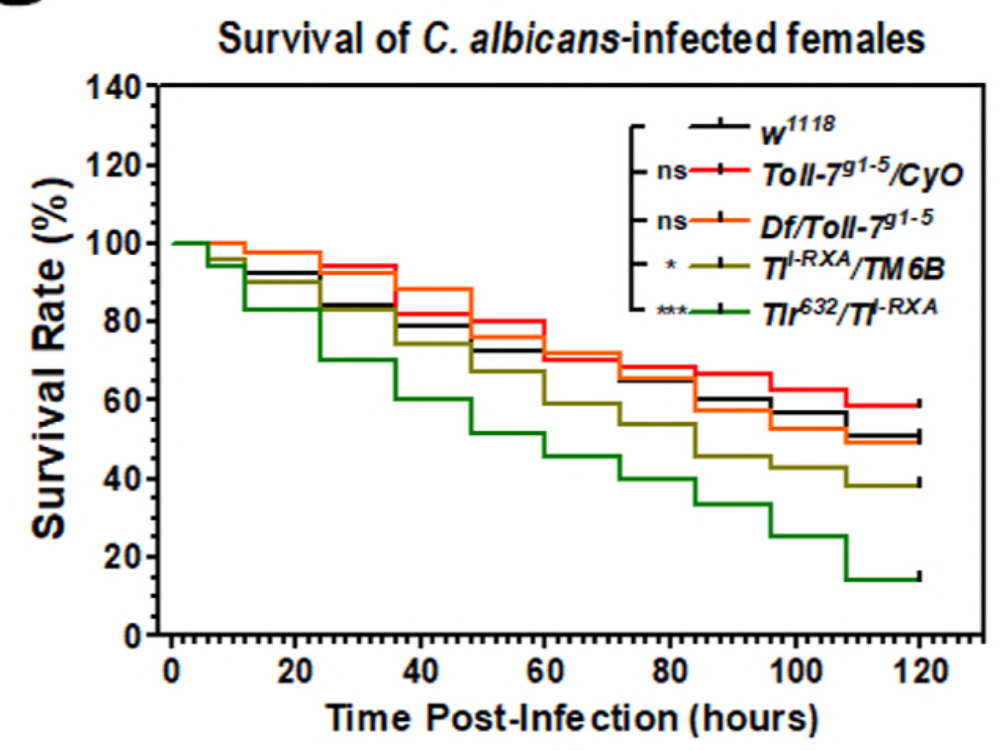

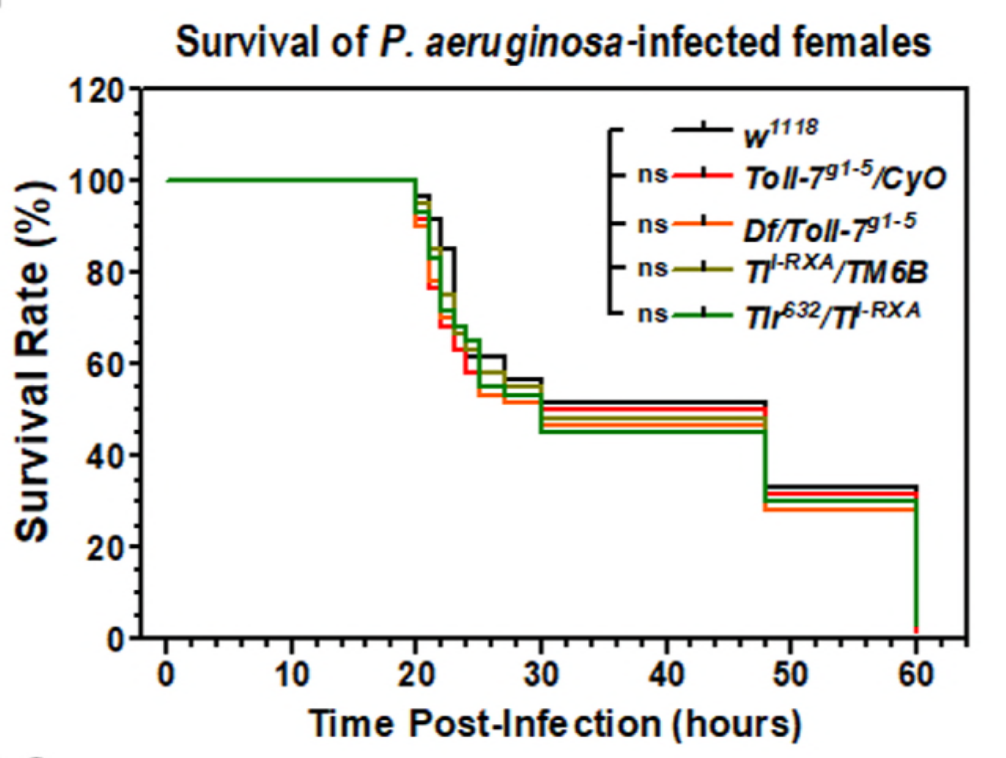

$\mathrm{H}$

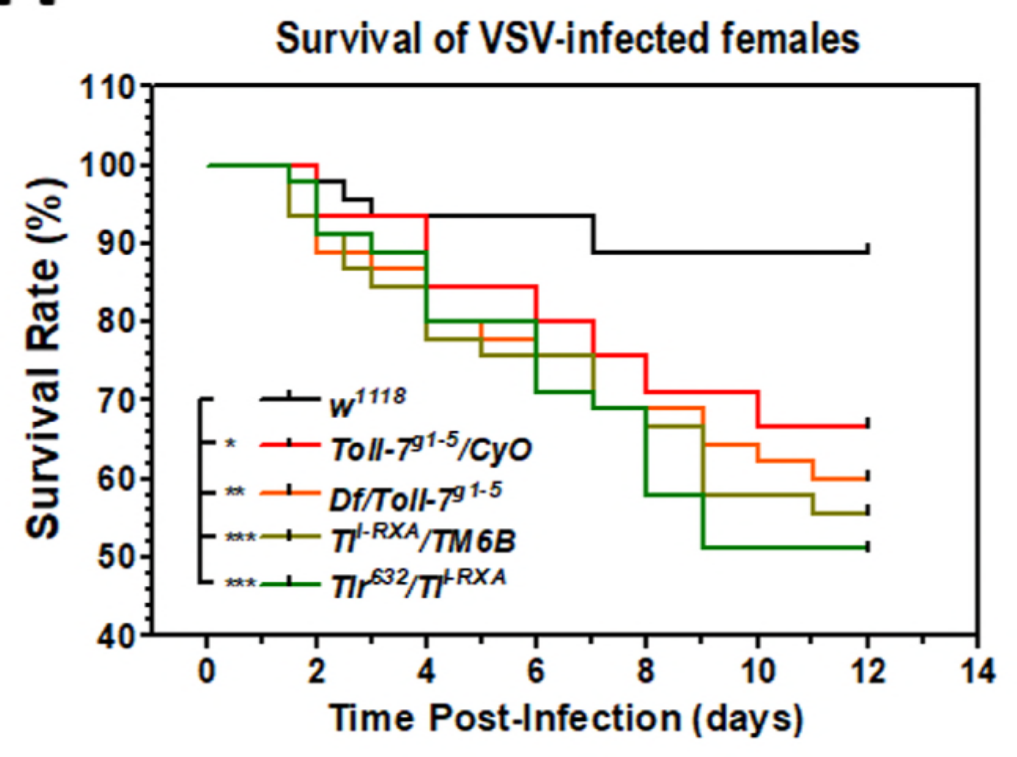

